\title{
The Self-Revelation and Cognition of VR-Facilitated Virtual Worlds: Towards a Phenomenology of Virtual Habitation
}

\author{
Matthew E. Gladden \\ Anglia Ruskin University \\ matthew.e.gladden@gmail.com
}

Received 28 February 2019; accepted 20 September 2019; published 31 January 2020

\begin{abstract}
In this text it is argued that immersion in virtual reality (VR) with the aid of contemporary VR equipment may offer access to novel types of virtual worlds that differ qualitatively from the "real" world and from other types of fictional worlds. The text begins by (a) distinguishing between VR systems, virtual environments, and virtual worlds; (b) showing how the virtual worlds facilitated by VR systems resemble and differ from the "virtual worlds" created in one's mind when, for example, reading a novel or watching a film; and (c) identifying necessary and optional elements of a VR-facilitated virtual world. Employing a phenomenological approach that draws on the thought of Ingarden and Norberg-Schulz, it is shown that a visitor to a VR-facilitated virtual world can (and frequently does) shift his or her conscious attention along three different "axes". First, one's attention can move "horizontally" between the media that disclose the virtual world through different senses. Second, one's attention can shift "vertically" between the virtual world's different ontological strata, including its layers of myriad atomic stimuli; distinguishable elements that possess spatiotemporal extension; assemblages of elements that have a context and relations but lack individual meaning; glimpses that build up a lattice of meaning and contribute to one's knowledge of the world; and the virtual world envisioned as a coherent mentally concretized whole. Third, one's attention can shift "interspatially" between the many different overlapping constituent spaces of the virtual world, including its perceptual, concrete, natural, built, identifiable, technological, emotional, social, economic, political, cultural, ecological, and possibility spaces. This triaxial phenomenological framework can shed new light on the rich and diverse ways in which VR-facilitated virtual worlds manifest themselves as emergent wholes constituted within human consciousness; also, it suggests approaches by which visitors might more proactively mentally explore and come to inhabit such virtual worlds.
\end{abstract}

Keywords: virtual reality; virtual worlds; transmediality; space; purely intentional objects; phenomenology; aesthetics; Ingarden; Norberg-Schulz 


\section{Introduction}

The development of increasingly sophisticated virtual reality (VR) systems involving 3D headsets, haptic feedback gloves, and other novel technologies is making it possible for individuals to immerse themselves in richly detailed, persuasive, interactive fictional worlds that differ not only from the "real" world of our natural everyday experience but also from the fictional worlds that we "enter" when watching a film or theatrical performance or reading a novel.

While significant research has been carried out regarding the physiological and engineering aspects of emerging VR technologies and the novel possibilities for interacting with individual objects in virtual reality, less attention has been given to (a) the unique nature of the new types of virtual worlds that VR technologies allow individuals to access and (b) the cognitive processes and conscious experiences through which a visitor may come to recognize, understand, and "inhabit" such a place as a true world - not simply as an illusory 3D space or random collection of objects.

This text employs a phenomenological approach to investigating such VR-facilitated virtual worlds; this is appropriate, given phenomenology's sensitivity to questions of appearance and reality, presence and absence, and objective manifestation and subjective intentionality (Sokolowski, 2000), coupled with the fact that virtual reality's uniqueness lies in the manner in which it seems to complicate or blur such binaries. This approach draws particularly on the phenomenological aesthetics and systems theory of Roman Ingarden and the architectural phenomenology of Christian Norberg-Schulz. Having established exactly what is meant by a "VRfacilitated virtual world", the text contends that such a virtual world is both a work of art and a multifaceted space, and a visitor is able to shift his or her conscious attention to and experience of such a world along three mental "axes". First, one's attention can be shifted "horizontally" between the senses that grant access to the different media through which the virtual world reveals itself. Second, one's attention can be shifted "vertically" between the various ontological strata of the virtual world, with each layer conveying qualitatively different types of information about it. And third, one's attention can be shifted "interspatially" between the many constituent spaces that make up the virtual world. This investigation provides a conceptual framework to support the design of virtual worlds as works of art in themselves, rather than simply as necessary ingredients for (or byproducts of) other forms of art like films, games, or novels; at the same time, it suggests mental techniques by which visitors to virtual worlds might become more savvy explorers and inhabitants of such emerging technologically "posthumanized" realms.

\section{Previous phenomenological analyses of VR}

The use of phenomenological approaches to investigate the nature of VR and virtual objects is well established. Indeed, Maluga (2006, p. 51) draws attention to a section in Ingarden's "The Architectural Work" (which Ingarden wrote in Paris in 1928) in which the Polish phenomenologist imagines a hypothetical technology that might someday be capable of creating a sort of "illusion" that makes it possible to perceive and interact with a building in threedimensional space, despite the fact that the sensations of the building are not generated by 
a corresponding real, physical, material mass (Ingarden, 1989a, pp. 272-73). As Maluga suggests, Ingarden essentially foresaw (and analyzed the implications of) VR technologies that are only today becoming feasible.

More recent phenomenologically oriented investigations relevant to virtual reality have included analyses of embodiment and intentionality in VR from the perspectives of MerleauPonty (Ajana, 2005; Cobián, 2008; McBlane, 2013; Bailey, 2016) and Stein (Fuentes, 2016); Heideggerian explorations of VR focusing on truth, inauthenticity, the world, and aesthetic experience (Coyne, 1994; Polt, 2015; Geng \& Peng, 2016); explorations of the connection between the lifeworld and virtual reality (Beeson, 2001; Deuze, 2014; Butnaru, 2015); analyses that relate Ingarden's aesthetics to virtual reality as art and narration (Ryan, 1999, 2001, 2015; Drazdauskas, 2006; Vilariño Picos, 2011; Przegalińska, 2014); frameworks for the design of virtual environments that draw on Norberg-Schulz's architectural phenomenology (Gladden, 2018b); broader phenomenological aesthetic analyses of virtual reality (Bekesi, 1999; Rabanus, 2009; Rousseaux, 2010); and more general phenomenological analyses of VR (Kornelsen, 1991; Murray, 1999; Schroeder, 2003; Heinzel \& Heinzel, 2010; Asanowicz, 2014). This text seeks to advance such phenomenological study by investigating the nature of the VR-facilitated virtual world qua world and our experience of it.

\section{The nature of virtual reality}

"Virtual reality" refers to an experience created by a particular type of system for generating visual, auditory, and (sometimes) haptic stimuli. Rabanus (2009) argues that the two factors that distinguish virtual reality from the experience of media like film or photographs are VR's immersiveness and interactivity. Here, "immersiveness" means that the images presented by VR gear are not perceived by users as just another small element within their natural environment (in the way that a book or television screen is); rather, VR blocks out a user's sensory experience of those surroundings to the greatest degree possible and replaces it with stimuli that offer the experience of a wholly fabricated environment. In this manner, a user does not simply "look at" a virtual environment in the way that one gazes at a painting hanging on a wall; rather, one experientially becomes a "visitor" to or "occupant" of the virtual space. "Interactivity", meanwhile, means that a visitor to a virtual environment does not simply passively experience it but can, to a significant degree, either consciously manipulate or unconsciously shape its contents. ${ }^{1}$

\section{Distinguishing VR technology, virtual environments, and virtual worlds}

While some authors use the terms "virtual environment" and "virtual world" interchangeably, others (e.g., Heim (1994) and Jerald (2016)) seem to suggest that immersive VR technologies may be used to create environments that fall short of constituting a virtual world. Here we

\footnotetext{
${ }^{1}$ See Rabanus (2009) for a more detailed account of various ways in which the "immersiveness" and "interactivity" of virtual reality have been (or can be) understood from within the phenomenological tradition.
} 
distinguish clearly between "virtual reality technology", "virtual environments", and "virtual worlds".

Contemporary virtual reality technology takes the form of a complex computerized cybernetic system incorporating (a) VR goggles, earphones, haptic feedback gloves, and other VR equipment that provides continuous sensory stimulation to its user; (b) motion detectors and other sensors that allow the system to detect real-time motor activity produced by a user, such as movements of his or her fingers or legs or the shifting of his or her gaze; and (c) software that is able to interpret the user's motor activity in real time, determine exactly how the perceived virtual environment should be altered by the user's actions, and then instantaneously transmit instructions to the VR goggles, earphones, gloves, or other equipment to generate stimuli corresponding to the virtual environment's new state.

A virtual environment is a perceived three-dimensional, interactive space that is experienced with the aid of VR technology. Like our "real" environment, a virtual environment is perceived by means of one's sense organs and is manipulated through motor actions; however, unlike our natural environment, its apparent three-dimensional contents are not isomorphic with real physical objects that endure in time.

A virtual world is more than just a virtual environment: it is a complex, coherent, mentally constituted place (or, more frequently, collection of places) that possesses a unique character and atmosphere, together with the full array of intelligent social agents and other objects that populate it, as well as the sum of their economic, political, and social interactions and relations and the "laws" that govern the structure and dynamics of objects within the world. A virtual world possesses a unique geography, culture, and history and is often created by its designer at least in part as a work of art. Such a "place" (Norberg-Schulz, 1980) is not simply a perceived three-dimensional space, although in the case of a VR-facilitated virtual world it is built upon and experienced through such spaces.

VR technology thus provides a stream of real-time sensory stimuli and the ability to detect and interpret user input that together allow a user to "occupy" a virtual environment within which he or she can move in three-dimensional space and perceive and manipulate objects. By exploring this environment, the visitor may eventually discern the existence and characteristics of a virtual world of places, people (or other intelligent social actors), events, stories, history, values, cultures, relationships, duties, and dynamics of growth and decline.

\section{The history of virtual worlds}

Contemporary VR technology is by no means the only tool for accessing virtual worlds; in fact, the creation of virtual worlds does not require any tools at all. Although contemporary VR technology is a powerful instrument for accessing virtual worlds that are highly immersive and interactive, human beings have been accessing simple virtual worlds of limited immersiveness and interactivity for millennia without the use of any specialized VR technologies (Ryan, 1999, 2001, 2015). Indeed, Lévy (1998) argues that human beings have always instinctively worked to virtualize our world and its contents in diverse ways, while Gunkel (2007) 
highlights the manner in which human reality has always incorporated elements of the virtual and illustrates how we move regularly in and out of virtual realms. ${ }^{2}$

For example, an orally transmitted folktale that includes a clear setting, characters, and plot enables its hearers to conjure into existence in their minds the corresponding virtual world as they picture (albeit nebulously) the events unfolding within the story and consciously or unconsciously manipulate the perspective from which they view those events. The development of technologies like clay tablets, papyrus, parchment, and the printing press allowed authors to create fixed, lasting, reproducible physical objects that serve as tools to aid geographically and temporally distant individuals to create within their minds the virtual worlds suggested by the associated stories' narratives (Ingarden, 1973, 1988). Similarly, paintings, operas, films, conventional non-VR computer games, and (to a lesser extent) sculptures, instrumental musical works, and other forms of art possess the ability to help human beings access and experience virtual worlds that demonstrate at least some immersiveness and interactivity.

\section{The ontological status of VR-facilitated virtual worlds}

The purpose of this text is not primarily to attempt to determine the ontological status of virtual worlds. However, it is worth noting that Ingarden's ontological frameworks suggest approaches by which one might analyze virtual reality (Ostrowicki, 2006). For example, Ingarden notes that when one makes an assertion about some everyday physical entity, one references two ontologically distinct objects: (1) the thing that one experiences as having a certain look, feel, sentimental value, and set of functional, artistic, economic, and social meanings and properties, and which exists only within the mind as a purely intentional object, and (2) some autonomous lump of matter that exists in space as a real object which provides an ontic fundament for the intentional object of one's experience and leads one to mentally experience that object in one way rather than another (Ingarden, 1988, pp. 229-231; Seifert \& Smith, 1994). ${ }^{3}$ When I look at a vase and say "This vase is pyramid shaped", I spontaneously intend the latter (real) object, but I am able to do so only because of my experience of the former (intentional) object. In such cases, we presume some natural, isomorphic causal relationship between the real and intentional: the reason I experience the intentional object of the vase as being pyramid shaped is because the chunks of matter that make up the associated real object are in fact arranged in a pyramidal shape. However, this correspondence breaks down in statements about fictional entities. When Hodgson (2015, p. 25) writes in his novel The Night Land of a future arcology that "the whole height of this pyramid exceeded seven miles", the only object about which an assertion is being made is a purely intentional one: the vast city-building

\footnotetext{
${ }^{2}$ For Deleuze, too, the "virtual" is always with us: in the Deleuzian understanding, the virtual is not opposed to the real but is already (a particular type of) reality, comprising a set of tendencies or possibilities of which some become "actualized" (Deleuze, 1994; Lovat \& Semetsky, 2009). Such a concept is only tangentially related to the "virtuality" of VR.

${ }^{3}$ Ingarden's realism thus lies not in claiming that the collection of entities that we refer to when speaking about "the real world" includes only real physical objects, but that it includes both real and intentional objects that are related in a particular natural, isomorphic manner. That correspondence distinguishes the real world from virtual worlds (including the worlds of dreams and fiction), which comprise purely intentional objects that lack an isomorphically related real component.
} 
described in the story. While there are indeed real physical objects (e.g., those underlying the drops of ink on a printed page or my brain's neurons) that shape my experience of that intentional object, it is not claimed that they have a pyramidal shape. Ingarden (1988, pp. 229-244) uses the term "quasi-judgment" to describe such assertions made within literary works about the contents of their fictional worlds.

The contents of VR-facilitated virtual worlds occupy a similar ontological category, and statements made about them are likewise "quasi-judgments" rather than "judgments". While our everyday natural world involves an isomorphic relation between intentional and real objects, a VR-facilitated virtual world does not: when we describe a particular virtual world as being "vast", "cold", "ancient", "unstable", or "spherical" or "possessing reduced gravity", we are speaking only of the purely intentional object that we experience in our minds - not of the arrangement of the lumps of matter (e.g., in a computer's hard drive or CPU) that make our experience of that world possible.

\section{Comparing a VR-facilitated virtual world with other virtual worlds}

A typical VR-facilitated virtual world can be compared with other virtual worlds in terms of (1) its degree of immersiveness, (2) its degree of interactivity, (3) the nature of the 3D environment through which it is experienced, and (4) its degree of determinacy. We can consider these characteristics in turn.

Immersiveness. The experience of closing one's eyes in a darkened room and listening to a piece of instrumental music can be deeply immersive, as can that of sitting in bed at night and reading a novel or of watching a film in a darkened cinema. A painting hanging on a gallery wall is less immersive because one is continually reminded by one's surroundings of the fact that one is standing in a gallery and not living in the world depicted in the painting. Thanks to its 3D capabilities and the way in which it blocks out extraneous stimuli, VR equipment can be highly immersive, although physiological and technological issues prevent it from matching the immersiveness of the "real" world (Jerald, 2016, pp. 45-52, 159-222).

Interactivity. The virtual world suggested by a painting is weakly interactive: one can view the canvas from different perspectives, but the visible contents remain fixed, displaying a single frozen, unchanging moment. Nevertheless, one can interact with the work to some degree by choosing how to interpret the painting's contents or enjoying some emotional response to it. The virtual world of a novel is more interactive, as a reader can move within the (imagined) scene being described, mentally rotating the space and choosing a perspective from which to view it. Nevertheless, a novel's interactivity is limited by the fixed sequence of its text's words. The story's author has already chosen what will happen next, and the reader's ability to shape the narrative is quite limited. The typical VR-facilitated virtual world is more interactive: a visitor can not only move around within the world and view it from various perspectives but can also shape the world's narrative by choosing what actions to perform (or not perform).

The nature of the $3 D$ environment. Films and paintings are essentially two-dimensional visual media; however, based on many perceived visual clues, when viewing them we instinctively accept the existence of a sort of 3D space. (For example, we naturally perceive some objects 
in a film as being "in front of" others; a film's stereophonic audio track also encourages us to experience a 3D space.) Objects presented in a painting or film thus break free of the surface's flatness to extend themselves not through "real" three-dimensional space but through "presented space"; in this way, the two-dimensional surface of the medium is temporarily rendered transparent (Ingarden, 1989c, p. 207). On the other hand, if when listening to a piece of instrumental music we happen to visualize a $3 \mathrm{D}$ space filled with a "rippling lake" or "flowery meadow", that environment is primarily the product of our imagination, not of visual perception. In the case of a novel, what we perceive visually are words on a page: the 3D space of the story and its visual details are imagined within our mind. Thanks to its stereoscopic nature, virtual reality is similar to the "real" world: we need not rely on our imagination to experience the 3D nature of its environment; we perceive it directly through our senses.

\section{Characteristics of virtual worlds accessed by different means}

\begin{tabular}{|c|c|c|c|c|c|}
\hline & & Immersiveness & Interactivity & $\begin{array}{c}\text { Nature of the 3D } \\
\text { environment }\end{array}$ & Determinacy \\
\hline \multirow{6}{*}{ 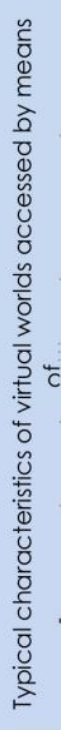 } & ... a painting & Weak & Weak & $\begin{array}{l}\text { Partly perceived } \\
\text { through the } \\
\text { senses, with } \\
\text { some imagining }\end{array}$ & Weak \\
\hline & $\begin{array}{r}\text {... an } \\
\text { instrumental } \\
\text { musical work }\end{array}$ & $\begin{array}{l}\text { Moderate } \\
\text { to high }\end{array}$ & Moderate & $\begin{array}{c}\text { Imagined } \\
\text { (insofar as such } \\
\text { an environment } \\
\text { exists) }\end{array}$ & Minimal \\
\hline & ... a film & $\begin{array}{l}\text { Moderate } \\
\text { to high }\end{array}$ & Moderate & $\begin{array}{l}\text { Partly perceived } \\
\text { through the } \\
\text { senses, with } \\
\text { some imagining }\end{array}$ & $\begin{array}{l}\text { Moderate } \\
\text { to high }\end{array}$ \\
\hline & ... a novel & $\begin{array}{l}\text { Moderate } \\
\text { to high }\end{array}$ & Moderate & Imagined & $\begin{array}{l}\text { Moderate } \\
\text { to high }\end{array}$ \\
\hline & $\begin{array}{r}\ldots \text { an } \\
\text { unconscious } \\
\text { dream }\end{array}$ & $\begin{array}{l}\text { Nearly } \\
\text { complete }\end{array}$ & Variable & Imagined & Weak \\
\hline & $\begin{array}{r}\ldots . \text { VR } \\
\text { technology }\end{array}$ & $\begin{array}{l}\text { Moderate } \\
\text { to high }\end{array}$ & Very high & $\begin{array}{l}\text { Perceived } \\
\text { through the } \\
\text { senses }\end{array}$ & $\begin{array}{l}\text { Moderate } \\
\text { to high }\end{array}$ \\
\hline \multicolumn{2}{|c|}{$\begin{array}{l}\text { Characteristics of } \\
\text { the "real world" }\end{array}$} & $\begin{array}{l}\text { Nearly } \\
\text { complete }\end{array}$ & Complete & $\begin{array}{l}\text { Perceived } \\
\text { through the } \\
\text { senses }\end{array}$ & High \\
\hline
\end{tabular}

Figure 1. 
Determinacy. Here "determinacy" relates to the processes of "concretization" described by Ingarden: some types of media tend to present a virtual world with few concrete details and many "gaps" in it; it is up to viewers to fill in these details (or "concretize" the work) within their consciousness. In this way, a work of art becomes a "common creation" of (a) the artist who put its determinate elements in place and (b) the recipients who mentally "co-create" the work in unique ways (Ingarden, 1964; 1989c; 2013, p. 291) through some combination of imagination and judgment. Other media tend to present a virtual world that is already highly "determinate"; the viewer has less need (or opportunity) to personalize or co-design the world by filling in the gaps in its content. A piece of instrumental music can cause listeners to visualize diverse virtual worlds or none at all; its world's contents are minimally determined. A painting gives us a clear glimpse into a single moment in time and space, but it tells us nothing about what was happening just before or after that moment or just beyond the edge of the canvas; the viewer is left to fill in such details. Conversely, novels often describe characters' histories and motivations in immense detail but allow readers the freedom to fill in most of the visual details of scenes. Films specify more visual details but leave characters' background and psychology more open to interpretation. A VR-facilitated virtual world more closely approaches the determinacy of the "real" world: its designer can specify both the visual characteristics, narrative, and history of the world with a rich level of detail, thus leaving less work (or freedom) for a visitor's imagination. Figure 1 reflects the combinations of immersiveness, interactivity, 3D environment, and determinacy that are typical of virtual worlds.

\section{Necessary and optional elements of a VR-facilitated virtual world}

Not all VR-facilitated virtual worlds are equally rich or engaging, but all possess certain basic features. The most essential elements are:

- Some built areas or a natural landscape (or both) within which one can move (Cudworth, 2014, pp. 73-98). Upon activating the VR system, a visitor becomes immersed in this terrain at a particular spot, with additional space extending around it that is waiting to be explored. In the case of VR computer games, built areas (e.g., buildings or settlements) are often scattered within a larger natural environment against which they are distinguished (Norberg-Schulz, 1980). It should be remembered that in a VR-facilitated virtual world, even the seemingly "natural" landscape has been artificially designed; however, the question of whether it is experienced as something "natural" or "artificial" depends on how deeply a visitor is immersed in the world in a given moment and the extent to which he or she consciously recalls the fact that the world is an artificial construct.

- The world's designer, who is implied but often not directly visible to visitors (Bartle, 2004; Cudworth, 2014). Traditionally, the designer of a VR-facilitated virtual world has been a human being (or team of human programmers, artists, and writers); however, part of a virtual world's design can increasingly be performed by AI (e.g., in the case of computer games that use procedural generation (Short \& Adams, 2017)), with limited oversight by human designers.

- Some apparent "laws of nature" that govern the structure and dynamics of objects within the world. A VR-facilitated virtual world's laws need not resemble those of the "real" 
world (Novak, 1991); for example, gravity may be stronger or weaker (Giddings, 2017), space may be non-Euclidean, or telepathy may be commonplace among the world's inhabitants. The nature of such laws is subject to the whims and abilities of the world's designer (Bartle, 2004, pp. 316-46).

- The human visitor to the virtual world, who experiences the world from a particular perspective and possesses a particular "avatar" or in-world (virtual) body capable of interacting with the world (Cudworth, 2014, pp. 237-41; Jerald, 2016, pp. 257-60). While the visitor has the experience of being "in" the virtual world, his or her physical body remains anchored in the "real" world and is thus not subject to the apparent laws of nature that govern objects existing (only) within the virtual world. To employ the terminology of Ingarden's anthropological model of the human being as a threefold emergent whole (Ingarden, 1970) - discussed in more detail below - the visitor's physical body is located outside of the virtual world, in the "real" world, while the visitor's intentional «I» of conscious awareness has entered and come to (temporarily) inhabit the virtual world, and the visitor's sensory-emotional "soul" straddles both realms.

Even the most basic virtual environment possesses the four aforementioned elements. What distinguishes a virtual world from a mere virtual environment is the fact that is has many of the following optional elements:

- Other apparent visitors to the virtual world (i.e., other users logged into a multiuser VR system) who manifest themselves as avatars (Jerald, 2016, pp. 257-60).

- "Native" inhabitants of the virtual world who appear not to be other human visitors; these may be non-player characters controlled by a computer game's AI (Bartle, 2004, pp. 287 94; Cudworth, 2014, pp. 241-56). In some cases, a visitor may lack the desire or ability to distinguish such artificial agents from the avatars of other human users.

- Particular persons (or entire populations) that are rumored (Bartle, 2004, p. 293), believed, or understood to exist, in addition to those agents that are directly encountered.

- Personal relationships between the visitor and the world's other visitors and inhabitants (Bartle, 2004, pp. 197-222).

- Social roles and obligations, political and economic structures, and customs and culture that have been centrally imposed by the world's designer or have emerged spontaneously through interactions between visitors and inhabitants (Bartle, 2004, pp. 297-312, 391-97).

- Paintings, sculptures, buildings, musical works, dances, theatrical performances, literary works, films, and other works of art experienced in the virtual world (Cudworth, 2014, pp. 315-39).

- A cosmogonic tale or detailed history of the overall world to date (Bartle, 2004, pp. 24243).

- A particular plot or storyline that unfolds with the visitor's participation (e.g., a mystery to be solved) (Jerald, 2016, pp. 225-227). 
- A particular "home" for the visitor (e.g., a specific house, den, or spaceship) that "belongs" to him or her in a special way amidst the larger territory of the virtual world (Cudworth, 2014, pp. 58-59).

- A "wilderness" full of natural wonders and wild animals (governed by AI) that surrounds the world's inhabited settlements (Cudworth, 2014, pp. 58-59). While such animals are experienced by the visitor as having evolved organically within the virtual world's natural ecosystem, they are typically not "natural" at all but have been crafted by a human designer (or by AI configured by a human designer).

- Lands "beyond", i.e. distant cities or realms that are known or rumored (Bartle, 2004, pp. 293) to exist but are not directly experienced.

The presence of any particular optional element in a virtual world is non-obligatory; however, a virtual world that has few such elements will feel more like a mere virtual environment and less like a fully realized world. The necessary and optional elements of a VR-facilitated virtual world are illustrated in Figure 2.

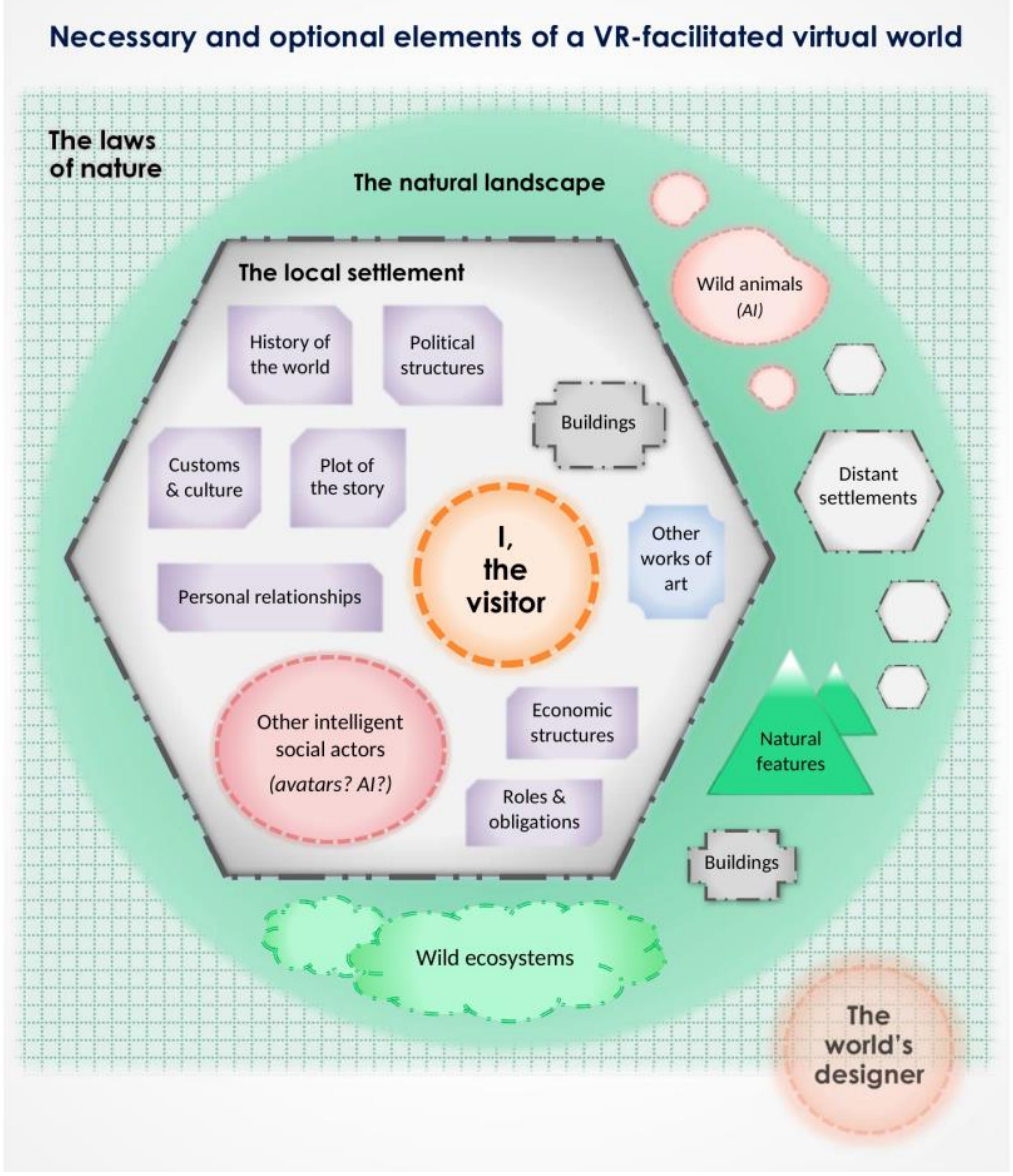

Figure 2. 
As has been investigated from various perspectives by, for example, Cobián (2008), Crick (2011), Klevjer (2012), Martin (2012), Asanowicz (2014), Keogh (2015), and Scriven (2015), the ways in which such elements of a virtual world may (objectively) manifest themselves to or be (subjectively) intended by a visitor are arguably as rich and diverse - though not exactly the same - as the ways that apply with elements of the "real" world. For example, another intelligent social actor (e.g., a non-player character controlled by a game's AI) within the virtual world may reveal itself through its physical form, gestures, facial expressions, and speech; it may aid or obstruct the visitor's exploration of the world; it can amuse, inform, or warn the visitor; and it can be befriended, harmed, remembered, or ignored by the visitor (Bartle, 2004, pp. 287-94; Cudworth, 2014, pp. 241-46).

\section{Formulating a triaxial model of conscious awareness of the VR-facilitated virtual world}

We are now in a position to investigate how a visitor to a VR-facilitated virtual world may come to know, understand, explore, and inhabit such a world in a manner that need not require journeying through various places within the world but instead involves altering the focus of one's conscious attention. It is proposed that there are (at least) three mental "axes" along which a visitor can shift his or her attention: an Ingardenian phenomenological analysis of the virtual world as a work of art suggests that attention can be shifted (1) "horizontally" between the senses that guide one in experiencing the virtual world, and (2) "vertically" between its different ontological strata, while an analysis grounded in Norberg-Schulz's architectural phenomenology suggests that a visitor can shift attention (3) "interspatially" between the many constituent spaces that make up the virtual world. A VR-facilitated virtual world comprises all three dimensions, (objectively) revealing itself differently through each of them, just as the visitor (subjectively) intends the world in different ways when focusing attention on each axis. We consider each axis in more detail below.

\section{First axis: Shifting attention between different senses and media}

Some forms of art are relatively "simple" insofar as they involve a single medium and perception via a single kind of sense organ. For example, the art of painting involves fashioning a pigmented surface that can be perceived with the aid of one's eyes, while music involves creating vibrations in the air that can be perceived with the aid of one's ears. Other forms of art are multimedial: Ingarden notes that songs with lyrics are neither simply a literary work nor a musical work; they are a hybrid that combines the two (Ingarden, 1989b). Such a song might have profound lyrics but an infantile melody, or vice versa. Similarly, a typical film is an organic whole combining visual imagery, music, and a literary work (Ingarden, 1966). An opera or musical (Ingarden, 1988, pp. 393-400) is intensely multimedial: it involves not only works of music but also architecture and painting (i.e., set design and lighting), fashion and stylization (i.e., performers' costumes and makeup), literature, live acting, and potentially dance. 
Moreover, from an Ingardenian perspective the fictional characters that appear in such media can themselves be understood as "works of art" as they are purely intentional objects created in viewers' consciousness with the aid of external objects corresponding to different media (Ingarden, 1988, pp. 281-326; Thomasson, 2005, 2009; Kroon, 2015; Uemura, 2019). Many contemporary fictional characters are transmedial creations: a single superhero or anthropomorphic talking bear might be presented through a series of films, TV shows, novels, comic books, posters, and computer games produced at different times by different authors. The character is not confined to a single work but exists across them all (Maj, 2015; Koskimaa, Maj, \& Olkusz, 2018). A VR-facilitated virtual world can be understood as similarly transmedial in nature: one comes to experience and understand the world as a whole by encountering various forms of art within the experience of VR. Such a virtual world is full of different works of art that one accesses through sight, sound, touch, or some combination of senses (Cudworth, 2014; Jerald, 2016).

Significantly, though, one never experiences all of a virtual world's constituent sensory and media elements equally at the same time. The reasons for that are suggested by Ingarden's anthropological model of the human being as a "relatively isolated system" 4 of semi-sheltered interior spaces and semipermeable physical, sensory, emotional, and intentional boundaries or "membranes" that regulate our engagement with the ultimate reality of the world in which we exist. According to this model, a human being exists as an emergent whole comprising a (1) physical body, (2) sensory-emotional "soul", and (3) intentional «I» of conscious awareness (Ingarden, 1970, pp. 66-99).

For example, imagine that one is playing a VR computer game set in a fictional medieval fantasy world and that within that virtual reality one is enjoying the experience of sitting at a table in a tavern and turning over an exquisite golden statue in one's hands, while across the table a local villager tells the story of how he just found the statue in a cave; in the background, mugs of ale clink, a bard sings a plaintive song, logs crackle in the fireplace, and rain batters a wooden door. At the same time, the VR equipment is continuously causally influencing one's physical body in a number of ways, from emitting photons from the VR goggles' display screens that impact one's retinas, to producing vibrations through the VR headphones' speakers that shift the hair cells in one's ears, to moving actuators in the haptic feedback gloves that compress one's fingers, to producing radio waves through the VR system's wireless transmitters that (as a side-effect) are partially absorbed by the cells of one's organism. One's physical body allows many of these influences (e.g., the photons of visible light, sound waves, and pressure on one's skin) to "enter" one's sensory-emotional soul in the form of sensory stimuli, while providing a barrier that filters out other influences (e.g., radio waves) and prevents them from being registered by one's sensory-emotional soul (Ingarden, 1970, pp. 66-99).

In each instant, one is, in a certain sense, "experiencing" in one's sensory-emotional soul all of the virtual world's sights, sounds, and feels. However, that experience is often semi-, sub-, or pre-conscious: in any given moment, the mind's mechanisms for focusing its attention allow

\footnotetext{
${ }^{4}$ Elsewhere we have explored applications of Ingarden's systems theory for designing the structures and dynamics of computer game environments through the software program Parinsula (Gladden, 2019, Version 0.9.4), which draws on Ingarden's (1974) thought to develop a real-time visualization of organism-like systems that can potentially be adapted for use in architecting VR-facilitated virtual worlds.
} 
only a tiny portion of the soup of sensory stimuli that fills one's sensory-emotional soul to enter the focus of attention of one's intentional «I», where particular stimuli are consciously pondered, interpreted, analyzed, and judged (Ingarden, 1970, pp. 66-99). Thus, in one moment, one's conscious attention might be focused on the speech of the villager seated across the table; in the next moment, one's attention may shift to the singing of the bard; in the next moment, it may shift to the feel of the statue in one's hands, the appearance of firelight reflecting on a bottle's surface, the style of the villager's clothing, or the pattern of decorative elements on the tavern's ceiling.

Knowledge of a VR-facilitated virtual world is built up within one's consciousness through receipt of diverse sensory stimuli corresponding to visual, auditory, and tactile elements. While all such stimuli are being registered continuously within one's sensory-emotional soul, one's intentional «I» can shift its conscious attention "horizontally" between different senses as they engage different media within the virtual world, as illustrated in Figure 3. In the case of a medium that involves multiple senses, in any given moment one's attention may be particularly focused on just one sensory facet of that medium.

\section{Sensory stimuli that grant access to different forms of media that can contribute to the experience of a VR-facilitated virtual world}

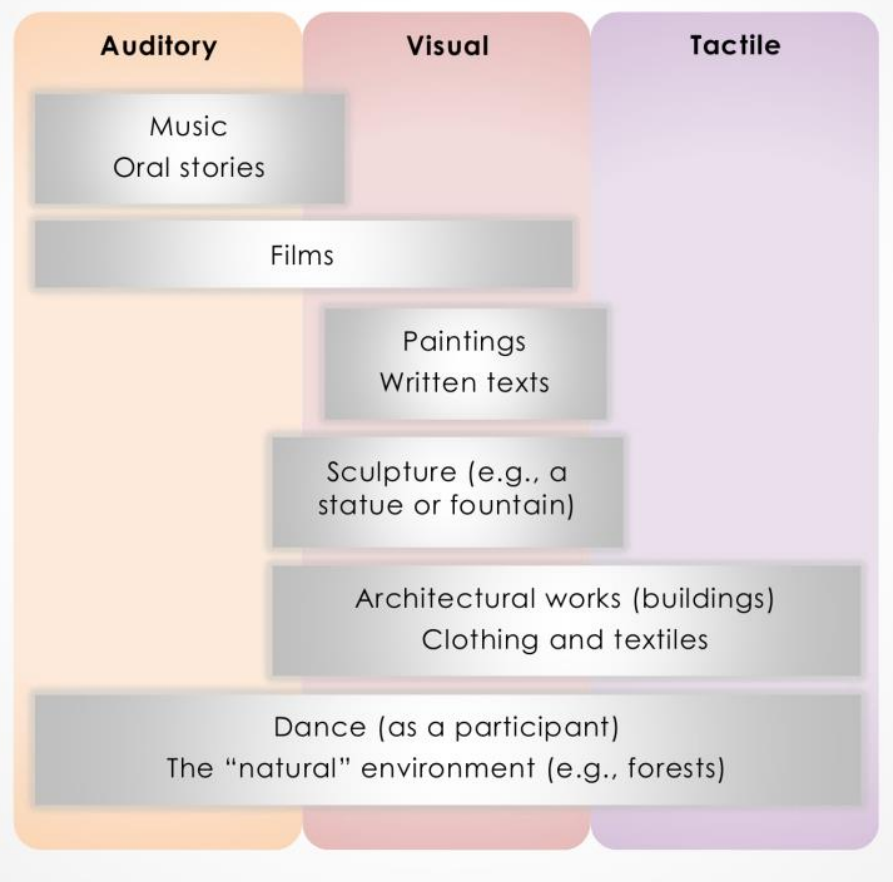

Figure 3. 


\section{Second axis: Shifting attention between ontological strata}

In addition to shifting one's attention "horizontally" between different senses, one can also shift one's conscious awareness "vertically" between strata of differing ontological natures. For example, imagine that within the virtual tavern described above one is currently focused on the speech of the villager sitting across the table as he recounts a local legend about a magical talking dragon to whom the golden statue once belonged. In his phenomenological account, Ingarden contends that such a legend or "literary work of art" is an emergent organic unity (Ingarden, 1988, p. 52; 1973, pp. 72-90) similar to the emergent whole of the physical body, sensory-emotional "soul", and consciously aware and intentional «I» that is a human being (Ingarden, 1970). As a literary work, the legend comprises at least (Ingarden, 1988, pp. 5354) four different layers that exist simultaneously (Ingarden, 1988, p. 53): (1) the phoneticlinguistic layer of particular sounds combined in a particular order (Ingarden, 1988, pp. 53, 57-99) that are generated by the villager's voice; (2) the semantic layer of individual semantic units (e.g., words like "magical" or "dragon") and sentences possessing more complex meanings (Ingarden, 1988, pp. 53, 99-280); (3) the aspectual layer of schematized "aspects", such as a description of the dragon's facial expression in a particular moment or a line of dialogue uttered by the dragon (Ingarden, 1988, pp. 53, 326-364; Sokolowski, 2000); and (4) the objectpresentational layer, which in turn comprises (a) intentional propositions that "present" an object by describing a state of affairs and (b) the objects that are thus intentionally "presented" (such as the dragon or cavern) and are intended in their fullness by a listener who has come to experience the objects through many of their aspects (Ingarden, 1988, pp. 53, 281-326, 364383; Sokolowski, 2000).

Within the virtual tavern, even if one remains continuously focused on the villager's tale, one's attention may shift between the raspy sound of his voice (Layer 1) in one moment, to pondering the etymology of the word "dragon" (Layer 2) in the following instant, to shuddering at the imagery in the scene that the storyteller is describing (Layer 3), to wondering about the dragon's psychology and motives (Layer 4). Together, these four layers form the literary work of art, which is a purely intentional object produced by and existing in the consciousness of those who experience it.

If, within the virtual tavern, other characters seated at a nearby table are speaking in some unfamiliar language (e.g., "elvish"), one might gather from the context that one of them is telling a story; however, one will be unable to access Layers 2, 3, or 4 of that literary work, as one does not understand the meaning of the words. Nevertheless, one can still access Layer 1: one can appreciate the patterns of rhythm, repetition and variation present in the speaker's voice and recognize the artistic qualities unique to that stratum, for example, by discerning whether the speech creates a sense of insistence and urgency through short, forceful tones or creates a dreamy, lullaby-like effect through soft, soothing, repetitive sounds.

Apart from the four strata of the literary work itself, there also exists what we might call "Layer 0 ", which is necessary for the literary work's existence but is not a part of it. This Layer 0 includes, for example, (a) the consciousness of the individual experiencing the literary work, which provides the "ontic fundament" within which the work (as a purely intentional object) is grounded (Ingarden, 1988, pp. 441-47) and (b) the real physical matter that exists in the world outside of the recipient and which is responsible for generating particular patterns of 
stimuli that help the recipient experience the literary work within his or her mind. In the case of an oral tale, Layer 0 would include the matter comprising the storyteller's vocal cords and the air molecules transmitting the soundwaves; in the case of a written literary work, it would include the matter comprising a printed page or a computer's display screen that produces patterns of light recognizable as letters. While the work of co-creating (alongside the work's author) and experiencing the literary work takes place in the recipient's consciousness, the external physical elements help guide the recipient to experience that particular literary work rather than another (Ingarden, 1988, pp. 449-51).

Ingarden argues that other forms of art possess differing numbers of strata: for example, a typical representational painting comprises the three strata of (1) the reconstructed aspect, (2) the represented and recreated material object(s), and (3) the literary theme (Ingarden, 1989c, pp. 139-51, 160-97); an architectural work of art (or "building") comprises the two strata of (1) the visual aspects and (2) the shape of the building (Ingarden, 1989a, pp. 265-77); a work of instrumental music possesses only a single layer comprising (1) an organized series of tones that lacks any semantic content per se but that can possess complex artistic qualities that elicit particular emotional responses in listeners and that differs from, say, the sounds of nature or a random series of tones generated by some electronic device (Ingarden, 1989b). For the purposes of this investigation of virtual worlds, it is not necessary to debate whether Ingarden's tally of the number of strata in each form of art is precisely correct; rather, we can draw more generally on Ingarden's insight that, for most types of media, a work of art is an emergent organic unity comprising multiple strata of differing natures and that one's attention can shift easily between these strata.

As is reflected in Figure 4, we would suggest that a VR-facilitated virtual world is a work of art that comprises at least five strata: (1) myriad atomic stimuli arranged in a pattern (e.g., the glow of particular pixels on an LCD screen); (2) distinguishable elements possessing extension (e.g., larger colored surfaces - comprising many pixels - that do not completely blend into one another); (3) assemblages of such distinguishable elements that possess a context and relationships but lack individual meaning (e.g., the complex shape of a dog or spaceship when first seen and recognized); (4) glimpses that gradually build up a lattice of meaning and contribute to one's knowledge of the world (e.g., one's experiences of a particular dog that accompanies one throughout the virtual world); and (5) the virtual world envisioned as a coherent mentally concretized whole. Such a virtual world is a composite transmedial work, and not every medium through which the world reveals itself will possess all five layers; however, the virtual world as a whole does possess them. Meanwhile, the virtual world owes the fact of its existence and the nature of its particular contents to a separate stratum of ontic fundaments (Layer 0) which is not, however, a part of the virtual world itself.

As Maluga (2006, p. 52) notes, the way in which Ingarden clearly distinguishes a work of art - as a purely intentional product of consciousness - from the ontic foundation upon which it relies opens the door for virtual buildings (and other virtual works of art of which one's experience is shaped by patterns of photons generated by a VR system's "atypical" physical substrate) to qualify as full-fledged works of art, just as truly as if they were shaped by lumps of matter comprising bricks, steel, or pigmented canvases. 


\section{Stratification of a VR-facilitated virtual world as a work of art}

\section{Layer 5}

The virtual world as a coherent mentally concretized whole

\section{Layer 4}

Glimpses that build up a lattice of meaning and contribute to knowledge

\section{Layer 3}

Anonymous assemblages

that possess

context and relations

\section{Layer 2}

Distinguishable elements with extension

\section{Layer 1}

Atomic stimuli arranged in a pattern relative to the visitor
This is the virtual world envisioned (though never exhaustively known) by its visitor as a coherent whole in all its potentiality, with all the things that a visitor imagines may already have occurred or may ever occur within the world. This object will differ significantly for each visitor who experiences "the same" virtual world.

Here a visitor receives fleeting, fragmentary glimpses that contribute to a growing knowledge of the virtual world. Through those aspects, the world begins to reveal itself semantically in greater depth; individual glimpses gradually build up a "skeleton" of meaning for the world, upon which the visitor will construct the holistic and coherent mentally concretized world.

The contents of this layer are "anonymous" (insofar as they do not yet possess individual significance) assemblages of distinct elements that seem to "cling together," displaying the kind of relationships possessed by a single thing's internal parts rather than by multiple disconnected things. Here a visitor recognizes such assemblages as kinds of things (e.g., "a dog" or "a starship") situated within a context - but not yet as things possessing unique personalities or individuality.

Here a visitor recognizes basic elements (e.g., colored surfaces or audible tones) comprising many atomic stimuli. Each element is spatiotemporally extended and bounded; it does not simply dissolve into the visual or auditory field. This is the lowest layer that is typically consciously perceptible; however, one's attention shifts spontaneously from Layer 2 to Layer 3, when possible.

Here a visitor experiences (but typically does not consciously perceive) myriad tiny points of light of differing brightness and color emitted by a screen in front of the visitor's face and the sound waves of millisecond-long audio samples generated by speakers positioned to the left and right of the visitor's head.

\section{Layer 0}

Ontic

fundaments of the virtual world
The visitor's consciousness provides the virtual world's immediate ontic fundament. The autonomous physical matter from which are formed a VR system's hard drive, screens, and speakers and the visitor's brain and other body parts provides a secondary ontic fundament that helps the visitor's consciousness experience the world in a certain way.

Figure 4. 


\section{Third axis: Shifting attention between constituent spaces}

The phenomenon of space is essential to one's experience of a VR-facilitated virtual world. Such a world both exists within and defines a space through which one can move and that is full of objects with which one can interact. However, as Norberg-Schulz's Heideggerian architectural phenomenology highlights, "space" is not a single unitary phenomenon but a collection of multiple overlapping spaces, each of which possesses its own unique nature (Norberg-Schulz, 1980; Erk \& Uluoğlu, 2013). The visitor to a virtual world exists simultaneously within all of these overlapping constituent spaces (or "subspaces") of the virtual world; however, in any given moment, the visitor's attention may be focused on that individual's position and activity within just one such space.

For example, imagine that a visitor to the virtual world described above (resembling a medieval fantasy realm) is traveling for the first time to a bustling market town to purchase some supplies; he or she might experience the crowded market square primarily as an economic space, within which opportunities exist for buying and selling goods and for making or losing money. On the other hand, a visitor who has already been to the market many times and is intimately familiar with all of the individual craftspeople and merchants who are selling their wares may experience the market primarily as a social space of friendships, acquaintances, loyalties, rivalries, and shared past encounters. Finally, a visitor who is simply passing through the marketplace in order to reach some distant destination - and who has no interest in the wares being sold or the persons selling them - may experience it primarily as a built space of physical structures, of stalls and wagons, of obstacles and openings, through which a path must be navigated to the opposite side.

Of particular significance is the distinction between what Ingarden calls real space and the presented space of a work of art like a novel or film. Here "real space" can be understood as the single objective space of three-dimensional, physical spatiotemporal objects (or endurants). The "presented space" that we experience in our consciousness when reading a novel or watching a film is a sort of simulation of real space: it is full of objects that claim to be real but in fact are not. Such presented space is not clearly bounded, but neither does it extend infinitely in the way that real space does (Ingarden, 1988, pp. 287-88). Both real space and presented space are true spaces, but there is no "spatial" bridge connecting them (Ingarden, 1988, p. 289); when a VR-facilitated virtual world is meant to accurately recreate some sliver of real space (e.g., a particular real-world city), the "link" between the real physical space and the presented space of its virtual replica exists in the consciousness of the visitor to the virtual world who temporarily "forgets" the simulated nature of the virtual world and sees in it the real-space original that it models (Ingarden, 1988, pp. 313-16).

Besides the real space within which the VR equipment and its user are located and the presented space of the virtual world, some of the other constituent spaces that make up the multifaceted space of a virtual world include:

- Perceptual space, the field within which we perceive three-dimensional objects to exist (Norberg-Schulz, 1980, p. 11; Erk \& Uluoğlu, 2013, p. 8). 
- Concrete space, which is the "intuitive three-dimensional totality of everyday experience", full of qualitatively differing regions like "up" and "down", "inside" and "outside", centers and paths (Norberg-Schulz, 1980, pp. 11-12, 59).

- The natural space (Erk \& Uluoğlu, 2013, p. 8) of the natural environment, which is defined by the threefold ground-horizon-sky boundary (Norberg-Schulz, 1980, p. 13).

- Built space, which is an enclosed, artificial analogue to (and recreation of) natural space that is defined by the threefold floor-wall-ceiling boundary (Norberg-Schulz, 1980, pp. 13, 58) and displays some architected combination of "centralization" and "longitudinality" (Norberg-Schulz, 1980, pp. 13, 59).

- The space of places, each of which possesses its own unique character, atmosphere, and genius loci (Norberg-Schulz, 1980, p. 7); this is distinct from the technologically facilitated space of flows that allows real-time interaction at a distance (Castells, 1997).

- Identifiable space, within which we experience some places as familiar - as "home" - and other places as foreign and alien (Norberg-Schulz, 1980, p. 22; Maier, 2000).

- The technological space (Ivanov, 2011) of tools, devices, and artificial systems that mediate human beings' interaction with one another, with their broader environment, and with themselves.

- The emotional space (Stangl, Wepman, \& White, 2012) of one's internal emotional experiences and all the memories, persons, places, events, and other objects that trigger emotional responses.

- The social space of social actors, social behaviors, social interactions, and social roles and expectations (Norberg-Schulz, 1980, p. 73; Erk \& Uluoğlu, 2013, p. 8).

- The axiological space, whose hierarchical systems of moral, aesthetic, and other values guide decision-making and action (Ruyer, 2016, p. 228).

- The economic space of labor, the production and consumption of goods and services, supply and demand, and money and finance (Cudworth, 2014, pp. 191-218; Norberg-Schulz, 1980, p. 73).

- The political space of power, military force, jurisdictional boundaries and affiliations, public policy, governance, protest, formalized collective decision-making, and the crafting and enforcing of laws (Norberg-Schulz, 1980, p. 73; Erk \& Uluoğlu, 2013, p. 8).

- The cultural space (Erk \& Uluoğlu, 2013, p. 8) of the arts and humanities, traditions, taboos, religious practices, and group identities.

- The ecological space (Rhodes, Chesser, \& Smith, 1996; Erk \& Uluoğlu, 2013, p. 8) of species, ecosystems, reproduction, growth, evolution, symbiosis, and competition for natural resources. 
- Possibility space, which includes not only that which is but also that which might be, along with the inherent capacities of objects and those laws governing their behavior and interaction that define what future possibilities exist and are more or less likely to be realized (DeLanda, 2011; Miller, 2006).

Some of these spaces (like political, economic, and cultural space) involve one's rich understanding of, attitudes toward, and interactions with structures and dynamics that only exist within Layers 3, 4, or 5 of the virtual world, and such spaces can only be accessed from within these layers. On the other hand, emotional space may be accessed not only through Layers 3, 4 , or 5 (e.g., if one ponders the joyfulness or tragedy of some story unfolding within the world) but also (differently) through Layers 1, 2, or 3 (e.g., if one tries to clear one's mind of any semantics or reasoning and simply allow oneself to be enveloped by the array of colored light that presents itself). Meanwhile, real space exists within the Layer 0 that undergirds the virtual world; although we presume such real space to exist, we do not experience it directly.

Figure 5 illustrates the three axes along which one's conscious attention can shift when experiencing a VR-facilitated virtual world; the virtual world manifests itself through all three axes and can be intended by the mind of a human visitor along all three.

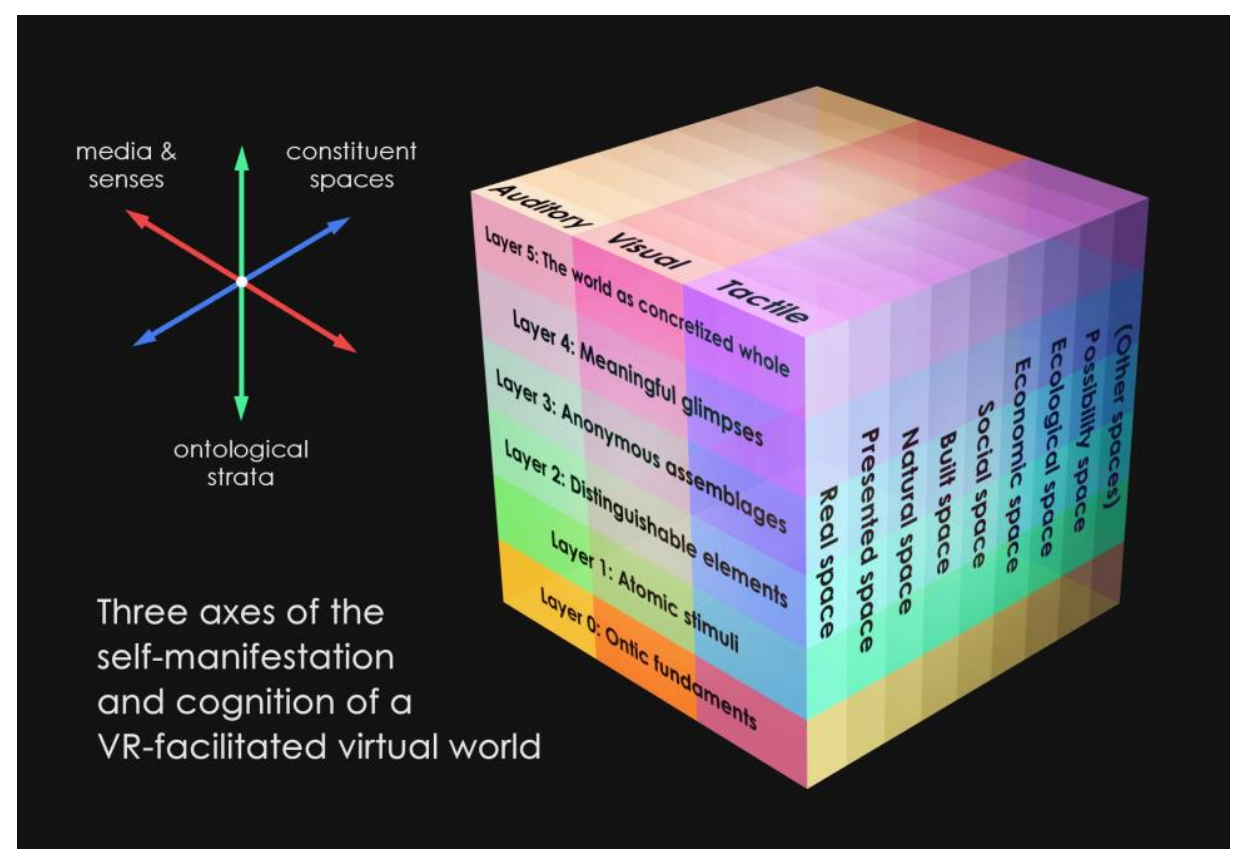

Figure 5. 


\section{Discussion}

The three axes can be illustrated by means of a thought experiment. Imaging donning a VR headset, headphones, and gloves and suddenly finding oneself immersed in a radically alien world that one has never visited before. Within this world, one's apparent (virtual) body takes the form of a ball of light floating within an immense, darkened chamber. There seems to be no gravity: one has no limbs or obvious means of propulsion but can rotate and move easily in any direction, as if propelled by thought alone. One gradually notices other glowing spheres moving lazily within the chamber, trailing bubbles and eddies behind them, as if the whole space were filled with some invisible liquid. The spheres' surfaces glow with intricate arrangements of light that slowly pulsate and transform, revealing what might be random patterns, natural camouflage, or meaningful symbols. Eventually, one discerns other larger objects of more complex form - vaguely organism-like, resembling bioluminescent amoebas. Periodically, one of these entities flickers and vanishes and then reappears in a distant spot, as if able to move between points without traversing the space between them. And in the farthest visible distance, defining the edges of the space, one makes out structures resembling honeycombs of coral, within which massive glimmering cubes of some metal-like substance are embedded. After some time, one also notices faint ambient sounds that seem to arrive from all directions - sounds almost like chimes or bells - almost like voices, but in no human tongue.

How would one go about making sense of such a VR-facilitated virtual world that is so wholly "de-anthropocentrized" and "posthumanized" (Gladden, 2018a) in its structure and dynamics? In the narrative just presented, one's attention is immediately seized by the visual aspects of the world because they are so exotic, rich, and intriguing. It is only after "exhausting" the initial dose of visual content that one's conscious awareness is led spontaneously to the less arresting and spectacular auditory elements of the world. However, one could subvert the natural dynamics of the world's "horizontal" first axis by purposefully directing one's attention immediately toward the world's auditory elements (e.g., if one has some prior reason for believing that the world is likely to reveal itself in significant ways through sound) or fixing one's attention permanently on the world's visual elements (e.g., if one has reason to believe that the soundtrack's contents are arbitrary and will not meaningfully disclose anything about the nature of the world).

With regard to the virtual world's "vertical" second axis of ontological strata, one might, for example, simply lap up the kaleidoscopic beauty of the world's fluctuating tapestry of colored surfaces (Layer 2), temporarily setting aside the fact that they represent distinct objects with distinct parts. As one begins to discern different objects - the floating spheres - that include diverse parts and move past one another within a three-dimensional space, one accesses Layer 3 of the virtual world. Over time, Layer 4 might manifest itself if one begins to sense that (a) some of the distant structures seem to have been "built" while others have "grown" organically, giving them differing significance, and (b) the spheres appear to be intelligent, social beings possessing rich (if mysterious) mental activity, and individual spheres possess unique personalities and motivations and differing roles and histories within the world. Finally, as one comes to appreciate the world (in both its seen and unseen elements) as an all-encompassing whole possessing its own order and atmosphere, the world manifests itself through Layer 5. On the other hand, if one purposefully strains to make out the individual pixels that combine 
to form the scene, then one is attempting to access Layer 1 of the virtual world. Likewise, if in particular moments the discomfort of wearing the VR goggles or the tug of the headphone cable reminds one that this is only a virtual experience (and that one is "actually" sitting in one's living room at home), then the existence of Layer 0 makes itself present, as one recalls the real-world physical matter that undergirds the experience of VR.

Finally, regarding the virtual world's "interspatial" third axis, it may require much time and interaction before all of the world's constituent spaces manifest themselves, and the order and rate with which they do so can depend on the reasons for one's immersion in virtual reality. If the virtual world is part of a new civilization-building computer game, one may quickly recognize and move into the world's political, economic, and strategic spaces (Erk \& Uluoğlu, 2013, p. 8). On the other hand, if the virtual world is a sort of exotic online chat room to which one has come to interact with friends (whose avatars are the other floating spheres), one may rapidly identify and occupy the world's social and emotional spaces. If the virtual world has been designed as a realm to be peacefully explored as a means of stress relief and relaxation, one might position oneself within its perceptual space, space of places, and emotional space. If it has been created as a part of a VR game in which one needs to navigate and escape from the world's devious "maze" as quickly as possible, one will be led to experience the world as perceptual, concrete, and built space. Finally, if the world has been constructed as a research tool in the field of astrobiology or xenobiology, one might naturally focus on the world's ecological or possibility space.

Even someone who is unfamiliar with the triaxial conceptual framework presented in this text would, over time, come to implicitly experience all three axes of the virtual world. However, by purposefully directing his or her conscious attention and ensuring that meaningful elements of the world are not inadvertently "overlooked", someone who understands the phenomenological framework formulated here can proactively employ it as a tool for helping the virtual world to reveal itself more quickly and fully than would naturally be the case.

\section{Conclusion}

The triaxial phenomenological model developed in this work recalls Proust's (2003, p. 237) observation that "The only real journey [...] would be to travel not towards new landscapes, but with new eyes [...]". A visitor to a VR-facilitated virtual world can discover and explore rich new contents within that world simply by shifting his or her conscious attention between its different spheres in a particular manner, without needing to travel from point to point within it; understanding such possibilities can help visitors to VR-facilitated virtual worlds - a group that will include ever more of us as VR technologies become more widespread - to become more adept at proactively shaping their experiences of spending time (and even $d$ welling) within such realms. At the same time, the model highlights the diverse ways in which a virtual world can reveal itself by simultaneously extending different parts of itself toward different facets of a visitor's mind. By fully exploiting such potential, the designers of VR experiences like those presented by computer games may be able to fashion more engaging, unique, and meaningful products that do not simply present isolated, unconvincing fragments of reality but that help conjure into existence coherent new inhabitable worlds. 


\section{References}

Ajana, B. (2005). Disembodiment and cyberspace: A phenomenological approach. Electronic Journal of Sociology, 7, 1-10.

Asanowicz, A. (2014). The phenomenology and philosophy of simulacra influence on the VR. Architecturae et Artibus, 6(1), 5-8.

Bailey, J. (2016). The body in cyberspace: Lanier, Merleau-Ponty, and the norms of embodiment. Christian Scholar's Review, 45(3), 211.

Bartle, R.A. (2004). Designing Virtual Worlds. Indianapolis: New Riders.

Beeson, I. (2001). Information systems in the lifeworld. In AMCIS 2001 Proceedings, 381.

Bekesi, J. (1999). Dufrenne and the virtual as an aesthetic category in phenomenology. Bulletin de La Société Américaine de Philosophie de Langue Française, 11(1), 56-71.

Butnaru, D. (2015). Phenomenological alternatives of the lifeworld: between multiple realities and virtual realities. SocietàMutamentoPolitica, 6(12), 67-80.

Castells, M. (1997). An introduction to the information age. City, 2(7), 6-16.

Cobián, M.T.R. (2008). Intencionalidad y virtualidad: Merleau-Ponty filósofo de la realidad virtual. Investigaciones Fenomenológicas, 1, 223-246.

Coyne, R. (1994). Heidegger and virtual reality: The implications of Heidegger's thinking for computer representations. Leonardo, 65-73.

Crick, T. (2011). The game body: Toward a phenomenology of contemporary video gaming. Games and Culture, 6(3), 259-269.

Cudworth, A.L. (2014). Virtual World Design. Boca Raton: A K Peters/CRC Press.

DeLanda, M. (2011). Philosophy and Simulation: The Emergence of Synthetic Reason. London: Continuum.

Deleuze, G. (1994). Difference and Repetition. Translated by P. Patton. New York: Columbia University Press.

Deuze, M. (2014). Media life and the mediatization of the lifeworld. In Mediatized Worlds (pp. 207-220). Springer.

Drazdauskas, L. (2006). Virtual reality as a phenomenon of art. Linköping: University of Linköping.

Erk, G.K., \& Uluoğlu, B. (2013). Changing Paradigms in Space Theories: Recapturing 20th Century Architectural History. International Journal of Architectural Research: ArchNet-IJAR, 7(1), 620.

Fuentes, P.M. (2016). The inseparability of consciousness from embodiment in the phenomenology of Edith Stein. In Edith Stein: Women, Social-Political Philosophy, Theology, Metaphysics and Public History (pp. 87-92). Springer.

Geng, Y., \& Peng, L. (2016). Three Aesthetic Dimensions of Virtual Reality from the Perspective of Heidegger. Journal of Dalian University of Technology (Social Sciences), 2, 021. 
Giddings, S. (2017). The Phenomenology of Angry Birds: Virtual Gravity and Distributed Proprioception in Videogame Worlds. Journal of Gaming \& Virtual Worlds.

Gladden, M.E. (2018a). A phenomenological analysis of the posthumanized future workplace. Kwartalnik Nauk o Przedsiębiorstwie, 48, 31-39.

Gladden, M.E. (2018b). A phenomenological framework of architectural paradigms for the usercentered design of virtual environments. Multimodal Technologies and Interaction, 2(4), article 80. https://doi.org/10.3390/mti2040080.

Gladden, M.E. (2019). Parinsula: A Generalized Relatively Isolated System Simulator (Version 0.9.4) [Computer software]. Indianapolis: Cognitive Firewall. http://cognitivefirewall.com/parinsula/

Gunkel, D. (2007). Thinking Otherwise: Philosophy, Communication, Technology. West Lafayette, IN: Purdue University Press.

Heim, M. (1994). The Metaphysics of Virtual Reality. New York: Oxford University Press.

Heinzel, A., \& Heinzel, T. (2010). The phenomenology of virtual reality and phantom sensations. Studia Universitatis Babes-Bolyai, Philosophia, 55(3).

Hodgson, W.H. (2015). The Night Land. Mineola, NY: Dover.

Ingarden, R. (1964). Artistic and aesthetic values. The British Journal of Aesthetics 4(3), 198-213.

Ingarden, R. (1966). Kilka uwag o sztuce filmowej. In Studia z estetyki, vol. 2 (pp. 309-29). Warszawa: Państwowe Wydawnictwo Naukowe.

Ingarden, R. (1970). Über die Verantwortung: Ihre ontischen Fundamente. Stuttgart: Reclam.

Ingarden, R. (1973). The Cognition of the Literary Work of Art. Translated by R.A. Crowley and K.R. Olson. Evanston: Northwestern University Press.

Ingarden, R. (1974). Über die kausale Struktur der realen Welt: Der Streit um die Existenz der Welt III. Tübingen: Max Niemeyer Verlag.

Ingarden, R. (1988). O dziele literackim: Badania z pogranicza ontologii, teorii języka i filozofii literatury. Translated by Maria Turowicz. Warsaw: Państwowe Wydawnictwo Naukowe.

Ingarden, R. (1989a). The architectural work. Translated by R. Meyer with J.T. Goldthwait. In Ontology of the Work of Art: The Musical Work, the Picture, the Architectural Work, the Film (pp. 255-316). Athens: Ohio University Press.

Ingarden, R. (1989b). The musical work. Translated by R. Meyer with J.T. Goldthwait. In Ontology of the Work of Art: The Musical Work, the Picture, the Architectural Work, the Film (pp. 3136). Athens: Ohio University Press.

Ingarden, R. (1989c). The picture. Translated by R. Meyer with J.T. Goldthwait. In Ontology of the Work of Art: The Musical Work, the Picture, the Architectural Work, the Film (pp. 137-254). Athens: Ohio University Press.

Ingarden, R. (2013). Controversy Over the Existence of the World: Volume I. Translated by A. Szylewicz. Frankfurt am Main: Peter Lang. 
Ivanov, V.V. (2011). Technological space and the ecology of technology. Herald of the Russian Academy of Sciences, 81(3), 305-309.

Jerald, J. (2016). The VR Book: Human-Centered Design for Virtual Reality. New York: Association for Computing Machinery and Morgan \& Claypool Publishers.

Keogh, B. (2015). A play of bodies: A phenomenology of videogame experience (Doctoral dissertation). Melbourne: RMIT University. Retrieved from https://researchbank.rmit.edu.au/view/rmit:161442/Keogh.pdf.

Klevjer, R. (2012). Enter the Avatar: The Phenomenology of Prosthetic Telepresence in Computer Games. In The Philosophy of Computer Games (pp. 17-38). Springer.

Kornelsen, J.A. (1991). Virtual reality? Marshall McLuhan and a phenomenological investigation of the construction of virtual worlds (Doctoral dissertation). Burnaby: Simon Fraser University.

Koskimaa, R., Maj, K.M., \& Olkusz, K. (2018). Introduction to Expanding Universes: Exploring Games and Transmedial Ways of World-building. International Journal of Transmedia Literacy, 4. https://doi.org/10.7358/ijtl-2018-000-intr

Kroon, F. (2015). Creationism and the problem of indiscernible fictional objects. In S. Brock \& A. Everett (Eds.), Fictional Objects (pp. 147-173). Oxford: Oxford University Press.

Lévy, P. (1998). Becoming Virtual: Reality in the Digital Age. Translated by R. Bononno. New York: Plenum.

Lovat, T., \& Semetsky, I. (2009). Practical mysticism and Deleuze's ontology of the virtual. Cosmos and History: The Journal of Natural and Social Philosophy 5(2), 236-249.

Maier, C.S. (2000). Consigning the Twentieth Century to history: Alternative narratives for the modern era. American Historical Review, 105(3), 807-831.

Maj, K.M. (2015). Transmedial world-building in fictional narratives. IMAGE, 22, 83-96.

Maluga, L. (2006). Autonomiczne rysunki architektoniczne. Wrocław: Oficyna Wydawnicza Politechniki Wrocławskiej.

Martin, P. (2012). A Phenomenological Account of the Playing-Body in Avatar-Based Action Games. In Philosophy of Computer Games Conference (pp. 29-31).

McBlane, A.A.J. (2013). Corporeal ontology: Merleau-Ponty, flesh, and posthumanism (Doctoral dissertation). Cardiff: Cardiff University.

Miller, R. (2006). Futures Studies, Scenarios, and the 'Possibility-space' Approach. In Think Scenarios, Rethink Education (pp. 93-105). OECD.

Murray, C. (1999). Towards a Phenomenology of the Body in Virtual Reality. Research in Philosophy and Technology, 19, 149-173.

Norberg-Schulz, C. (1980). Genius Loci: Towards a Phenomenology of Architecture. New York: Rizzoli.

Novak, M. (1991). Liquid architectures in cyberspace. In M. Benedikt (Ed.), Cyberspace: First Steps (pp. 225-54). Cambridge, MA: The MIT Press.

Ostrowicki, M. (2006). Wirtualne realis. Estetyka w epoce elektroniki. Kraków: Universitas. 
Polt, R. (2015). A Heideggerian Critique of Cyberbeing. In Horizons of Authenticity in Phenomenology, Existentialism, and Moral Psychology (pp. 179-197). Springer.

Proust, M. (2003). In Search of Lost Time, Volume 5: The Prisoner and The Fugitive. Translated by Carol Clark and Peter Collier. New York: Penguin.

Przegalińska, A. (2014). Fenomenologia istot wirtualnych (Doctoral dissertation). Warszawa: Uniwersytet Warszawski.

Rabanus, C. (2009). Virtual reality. In Handbook of Phenomenological Aesthetics (pp. 343-349). Springer.

Rhodes, Jr., O.E., Chesser, R.K., \& Smith, M.H. (Eds.). (1996). Population Dynamics in Ecological Space and Time. Chicago: University of Chicago Press.

Rousseaux, F. (2010). Phenomenological Issues in Virtual Reality: Technical Gestures Directed like Virtual Pieces of Performing Art. Universitatis Babes-Bolyai, Philosophia, 61.

Ruyer, R. (2016). Neofinalism. Translated by A. Edlebi. Minneapolis: University of Minnesota Press.

Ryan, M.-L. (1999). Immersion vs. Interactivity: Virtual Reality and Literary Theory. SubStance, 28(2), 110-137.

Ryan, M.-L. (2001). Narrative as Virtual Reality: Immersion and Interactivity in Literature and Electronic Media. Baltimore: The Johns Hopkins University Press.

Ryan, M.-L. (2015). Narrative as Virtual Reality 2: Revisiting Immersion and Interactivity in Literature and Electronic Media. Baltimore: The Johns Hopkins University Press.

Schroeder, R. (2003). Beyond Presence and Copresence: A Phenomenological Account of Experiences in Shared Virtual Environments. In Proceedings of Presence 2003: Aalborg University, Denmark, October 6, 2003.

Scriven, P. (2015). The phenomenology of the 'Other' in computer game worlds. Games and Culture. https://doi.org/10.1177/1555412015615294

Seifert, J., \& Smith, B. (1994). The Truth About Fiction. In W. Galewicz, E. Ströker, \& W. Stróżewski (Eds.), Kunst und Ontologie: Für Roman Ingarden zum 100. Geburtstag (pp. 97-118). Amsterdam: Editions Rodopi B.V.

Short, T., \& Adams, T. (Eds.). (2017). Procedural Generation in Game Design. New York: A K Peters / CRC Press.

Sokolowski, R. (2000). An Introduction to Phenomenology. Cambridge: Cambridge University Press.

Stangl, A., Wepman, J., \& White, D. (2012). Moodcasting: home as shared emotional space. In CHI'12 Extended Abstracts on Human Factors in Computing Systems (pp. 1303-1308). ACM.

Thomasson, A.L. (2005). Ingarden and the Ontology of Cultural Objects. In A. Chrudzimski (Ed.), Existence, Culture, and Persons: The Ontology of Roman Ingarden (pp. 115-36). Frankfurt: ontos verlag. 
Thomasson, A.L. (2009). Fictional entities. In A Companion to Metaphysics (2nd ed.) (pp. 10-18). Oxford: Blackwell.

Uemura, G. (2019). Demystifying Roman Ingarden's purely intentional objects of perception. In N. de Warren \& S. Taguchi (Eds.), New Phenomenological Studies in Japan. Springer.

Vilariño Picos, M.T. (2011). La Hermenéutica constructiva en/del ciberespacio. De William Gibson a Roman Ingarden. Ámbitos: Revista de Estudios de Ciencias Sociales y Humanidades, 25, 73-83.

Matthew Gladden's research interests include phenomenological aesthetics and the philosophical aspects of virtual reality technologies. He is especially interested in applying the thought of Roman Ingarden and Christian Norberg-Schulz to a phenomenological architectural analysis of gameworlds and other virtual worlds. He has taught philosophical ethics at Purdue University, served as Associate Director of the Woodstock Theological Center at Georgetown University, and served as a guest lecturer in the Institute of Computer Science of the Polish Academy of Sciences.

The editorial and publishing process of this publication has been financed by the Ministry of Science and Higher Education from the funds for the dissemination of research (DUN) within the framework of publishing activity, contract no. 711/P-DUN/2019, period of implementation: the years 2019-2020. 